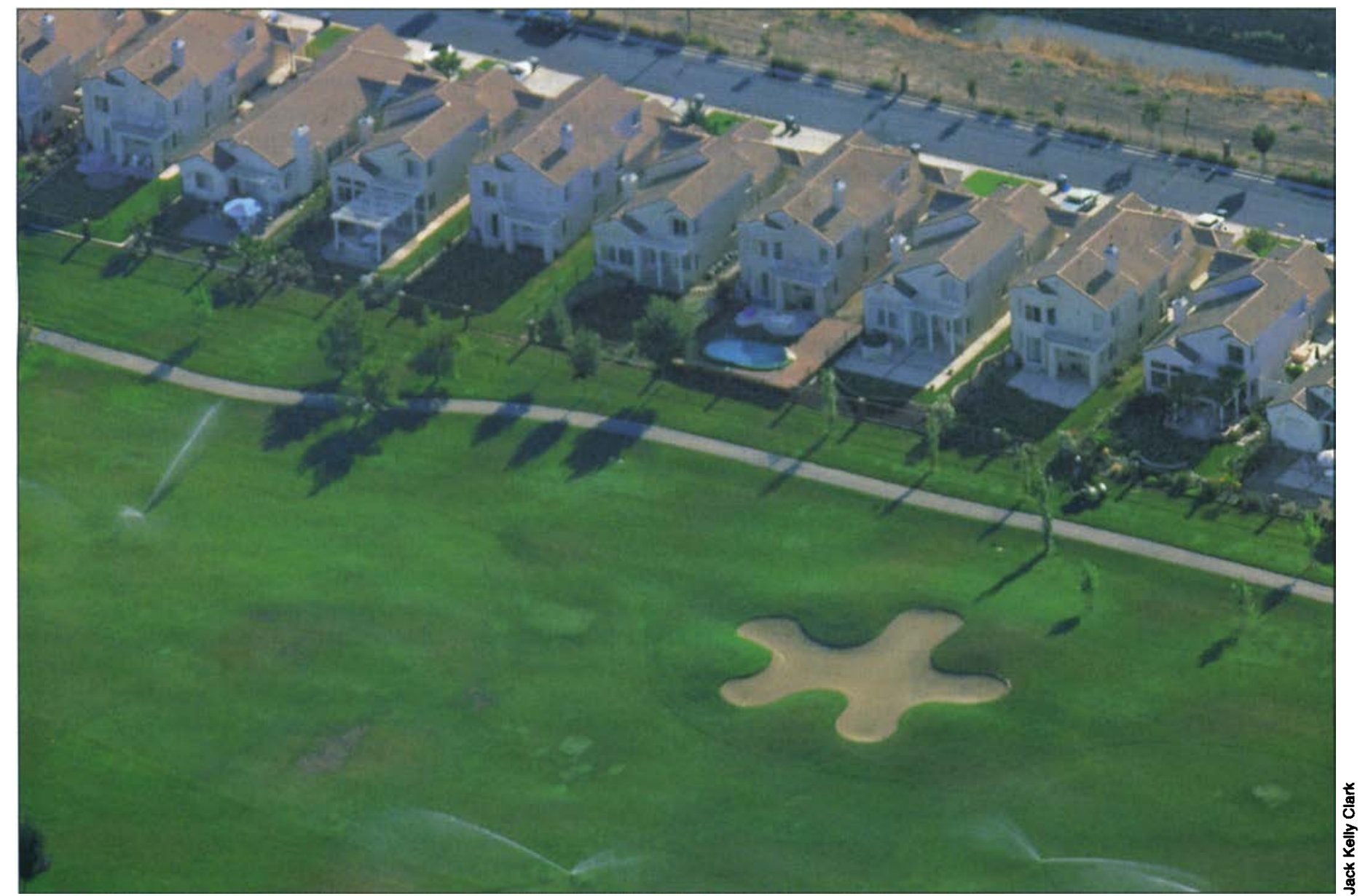

In addition to crops throughout the state, CIMIS weather data is used to Irrigate golf courses, parks and cemeterles more efficiently.

\title{
Publicly funded weather database benefits users statewide
}

\author{
Doug Parker Daniel R. Cohen-Vogel a Daniel E. Osgood a David Zilberman
}

The California Irrigation Management Information System (CIMIS), developed and operated by the California Department of Water Resources, was assessed using a UC Cooperative Extension survey and the CIMIS user database. We found that the benefits of the program far outweigh the state cost of about $\$ 850,000$ per year. Statewide, 363,816 agricultural acres are under CIMIS, with annual estimated benefits of $\$ 64.7$ million.

Fresno and Kern counties recelve the largest net benefits, while Santa Barbara and Ventura counties have the highest benefits per acre. According to our calculation, statewide agricultural water applications are reduced by 107,300 acre-feet annually. Initially designed for irrigation management, CIMIS weather information stations benefit a host of other agricultural and nonagricultural activities such as pest control and water use by parks and golf courses. Using general economic principles, we also assessed alternative scenarios for future management of CIMIS, such as charging fees or continuing its operation as a public-sector resource.
Government expenditures in agriculture are subject to growing scrutiny, and criteria for their selection and continued support are increasingly tied to a project's net economic benefit rather than its public benefits alone. We evaluated the returns of one such government investment, the California Irrigation Management Information System (CIMIS), and found that it provides significant benefits through both traditional and unpredicted alternative applications.

CIMIS was created in 1982 by the California Department of Water Resources (DWR) and UC to encourage weather-based, water-budgeting methods of irrigation. Using evapo- 


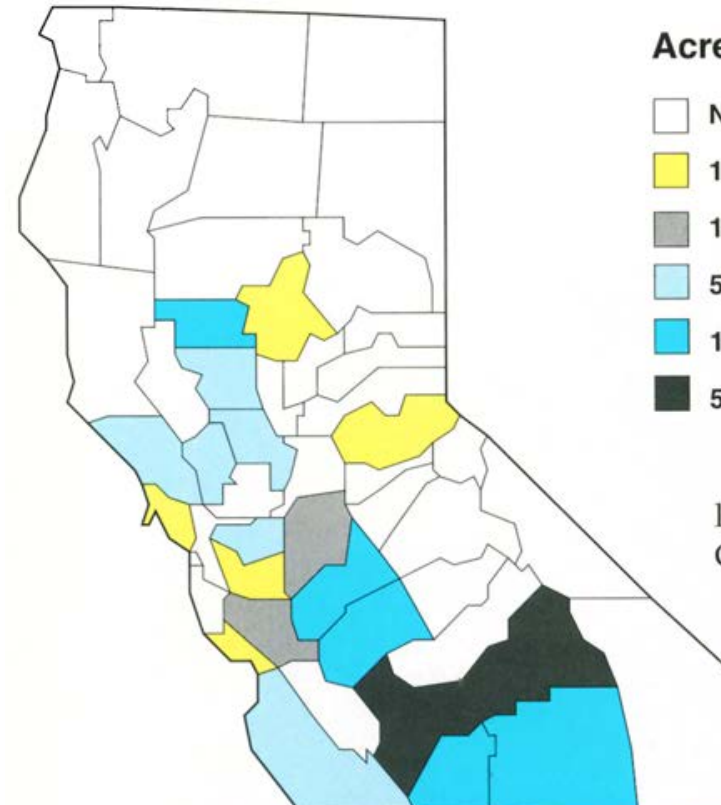

Acres adopted

Not surveyed

$1-1,000$

$1,000-5,000$

$5,000-10,000$

$10,000-50,000$

$50,000+$ private land). The estimated statewide cost to DWR and its local cooperators for building and operating CIMIS is approximately $\$ 850,000$ per year.

Who uses CIMIS?

In 1997, we con-

ducted and ana-

lyzed 291 telephone interviews with CIMIS users in an attempt to understand who benefits from the system and how, what factors encourage its use, and how much users might be willing to pay for the information. CIMIS users are growers, urFig. 1. CIMIS adoption in California counties

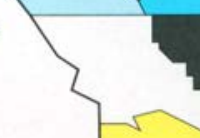

ban irrigators, farm consultants, media sources, researchers and various public agencies. Tree- and vine-crop growers are transpiration (ET) data, farmers are able to replenish the water used by their crops and to calculate the amounts lost due to irrigation nonuniformities (Grattan et al. 1998). CIMIS is the only public source of ET data in California. The data it generates are provided as a wholesale good to irrigation consultants, newspapers, radio stations, the National Weather Service, water districts, and other freely accessed databases (such as the UC Statewide Integrated Pest Management Project's IMPACT and Fresno State's ATI Net). Some users then resell the data, often in a refined or augmented form, adding value to the original information. Users may also access the CIMIS system directly via modem or the Internet.

Today CIMIS has both local-agency and private-sector support. In mid2000 , the state owned fewer than half of the more than 100 weather stations, although it continued to provide the centralized computer facility as well as calibration and quality control. Local agencies purchase and maintain their own stations and provide the sites (from 9 to 20 acres per station, often on of pest-control advisors (PCAs) are estimated to be using CIMIS. While this study focused primarily on irrigation benefits, the benefits in pest control may be just as significant.

CIMIS adoption and benefits increase with crop value and water costs. Users with plentiful and inexpensive water use CIMIS for purposes other than water conservation, such as pest control. Within a region, heterogeneity among farm-specific factors determines patterns of adoption. In addition to water costs and crop value, irrigation technology, farm size, land quality, and water-district and farmadvisor educational programs are important determinants of CIMIS adoption. When many of the above determinants do not vary, adoption of CIMIS is dependent upon the level of human capital (e.g., education, experience) that the grower brings to irrigation management.

A large increase in the number of growers and consultants using CIMIS occurred around 1989, at the height of the drought (Parker and Zilberman 1996); the number of registered users increased three-fold between 1986 and 1993. Urban irrigation consultants credit the Water Conservation in Landscaping Act of 1990 (AB 235) with increasing their client base and influencing decisions to use CIMIS. Similar laws, in combination with weather uncertainty, offer major incentives for adoption of CIMIS and other water-efficient technologies.

\section{Estimating irrigation benefits}

The methodology devised to estimate the statewide benefits from CIMIS involved a two-tiered survey. We first surveyed a subset of CIMIS users to collect data on actual benefits, particularly yield and water-use changes attributed to CIMIS adoption. This information was used to estimate benefits per acre of each crop in a user's portfolio. Growers accrue increased benefits because of improved yields and reduced water costs. These benefits are functions of economic variables such as prices of crops and water, but they also depend on the efficiency of water use in response to local weather. To predict benefits to in- 
dividual growers, a linear benefit equation was fitted (Osgood et al. 1997). (The reduced-form equation was $B=\beta+\beta R+\beta W$, where $B$ is total dollar beneffits peer acre, $R$ is revenue per acre, and $W$ is a biological crop water-use proxy based on the crop's ET rate and local weather. $W$ was multiplied by the price of water to convert from acre-feet of water to dollars.)

We then conducted a second survey of UC Cooperative Extension advisors, who provided 104 estimates of the fraction of adoption by specific crop and county. The per-acre benefits from the first survey were combined with these acreage estimates to arrive at an estimate of county and statewide benefits from CIMIS.

We estimated a statewide total of 363,816 agricultural acres in 22 counties under CIMIS and calculated the annual statewide agricultural benefits to be $\$ 64.7$ million (table 1 ). Fresno and Kern counties, with the greatest number of acres using CIMIS, also receive the largest net benefits. Santa

TABLE 1. Statewide CIMIS benefits, aggregated by county

\begin{tabular}{lrr}
\hline \hline County & Benefits & $\begin{array}{r}\text { Benefits } \\
\text { per acre }\end{array}$ \\
\hline & \multicolumn{1}{c}{$\$$ /acre } \\
Butte & 41,400 & 230 \\
Colusa & 305,800 & 90 \\
Contra Costa & 667,600 & 86 \\
El Dorado & 71,340 & 296 \\
Fresno & $10,590,000$ & 125 \\
Glenn & $3,494,000$ & 127 \\
Kern & $29,680,000$ & 265 \\
Kings & $1,848,000$ & 245 \\
Merced & $2,024,000$ & 48 \\
Monterey & $3,068,000$ & 357 \\
Napa & 1,625 & 1 \\
Orange & 27,610 & 115 \\
Riverside & $1,486,000$ & 424 \\
San Bernardino & 6,409 & 160 \\
San Diego & 3,235 & 48 \\
San Joaquin & $3,221,000$ & 203 \\
Santa Barbara & 16,800 & 560 \\
Santa Clara & 21,750 & 73 \\
Sonoma & 549,100 & 209 \\
Stanislaus & 809,100 & 51 \\
Tulare & $3,068,000$ & 324 \\
Ventura & $3,655,000$ & 674 \\
\hline Total benefits & & $\$ 181$ \\
Average benefits per acre & & \\
& & \\
\hline
\end{tabular}

Barbara and Ventura counties have the highest benefits per acre, due to high value crops, such as winegrapes and tree nuts, and the high cost of water. Extrapolating from these results, we estimate that agricultural use of CIMIS reduces statewide applied water by 107,300 acre-feet annually.

\section{Other agricultural benefits}

This analysis of CIMIS does not have the scope or the data to quantify several known additional benefits to agriculture. However, qualitative data demonstrated that CIMIS is used extensively by PCAs in integrated pest management (IPM) programs. Growers also access CIMIS when making their own pest-management decisions. Benefits from CIMIS may thus include less pesticide use (in pounds), fewer applications (a benefit to worker safety as well as a cost savings), higher quality crops, and reduced risk of crop damage.

Although we have estimated only changes in water use and volume of output, CIMIS also produces gains in crop quality from improved water management and pest control. Better water management can mean healthier, larger fruits and reduced problems from mold. Increased fruit size is often associated with higher prices (Parker and Zilberman 1993), while decreased pest damage can improve selling price by increasing quality grades. Finally, CIMIS may reduce the risk to crops associated with weather variability, allowing more stable farm revenues.

\section{Nonagricultural benefits}

Golf courses, parks, cemeteries and landscapers use CIMIS to keep lawns and shrubs healthy with minimum water use. We estimated 8,778 acres of turf and landscaping under CIMIS. This acreage is concentrated in Southern California and in Santa Clara County. Users estimated that they reduced applied water by 5,793 acre-feet annually, saving $\$ 2.3$ million. In many cases (school districts, parks) these savings accrue to government entities.

For example, the California Department of Transportation uses CIMIS to schedule irrigation of 300 acres of ornamentals and shrubs in the Fresno area. The agency reports a $20 \%$ to $40 \%$ decrease in applied water, at a savings of $\$ 1,500$ per year. At least two water districts use CIMIS to allocate water supplies or set water prices. The Irvine Ranch Water District uses the information to set its yearly block price rates,

TABLE 2. Potential CIMIS fee structures: pros and cons

\begin{tabular}{lll}
\hline \hline Fee structure & \multicolumn{1}{c}{ Pros } & \multicolumn{1}{c}{ Cons } \\
\hline $\begin{array}{l}\text { Phone charge (per call or per } \\
\text { minute) }\end{array}$ & $\begin{array}{l}\text { Easy billing; users pay only for } \\
\text { what they need }\end{array}$ & $\begin{array}{l}\text { Sensitive to speed of modem; } \\
\text { risk of information sharing }\end{array}$ \\
$\begin{array}{lll}\text { Periodic subscription (monthly, } & \text { Easy billing; recognizes temporal }\end{array}$ & Risk of information sharing
\end{tabular}
seasonal, or annual)

Other flat fees (based on acreage, crop, or other characteristics)

Charge on output (levied through commodity groups)

Charge on input use (levied through water districts or agrochemical dealers)

Charge to information suppliers (based on number of users or inputs used in a service area) nature of users' data needs

Charges according to potential gains

Charges based on actual gross revenue; collection infrastructure already in place; reduces information-sharing risk

Encourages input conservation by charging for input use; reduces information-sharing risk

Burden of monitoring and charging on local agencies/companies with greater control over service area which reduces sharing risk and administrative costs; suppliers have incentive to improve the information
Hard to monitor; excludes some user groups; information-sharing risks; fairness issues of price discrimination

No input conservation incentive; excludes some user groups

Monitoring difficulties (e.g., groundwater availability); excludes some user groups

Monitoring difficulties; risk of information sharing; limits access 


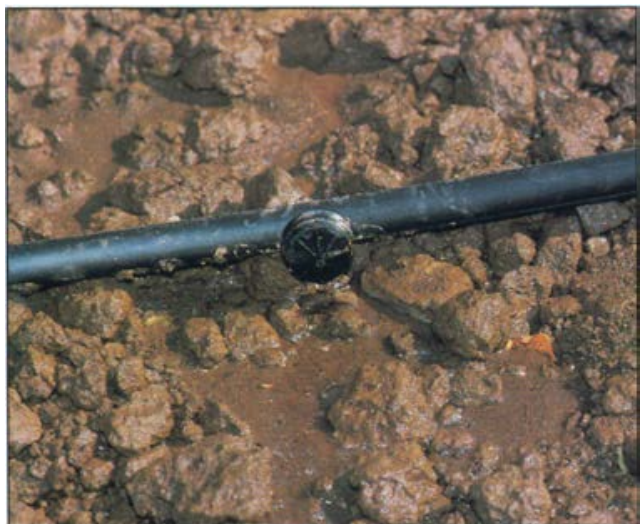

CIMIS data saves an estimated 107,000 acre-feet of water annually in California.

saving an estimated 1,500 acre-feet per year or $\$ 236,250$. The Fox Canyon Groundwater Management Agency uses CIMIS to set its water allocations, and the Monterey County Water Resources Agency is considering a similar approach.

Many other CIMIS uses are unrelated to water management (Cohen et al. 1998). One private investigator accesses CIMIS to determine road friction variables for legal cases involving road accidents. The Santa Clara County Vector Control District uses it to track mosquito populations. A geothermal power plant incorporates CIMIS historic weather records in its temperature regulation, and the San Diego Air Quality Control Board uses CIMIS solar radiation measurements to help monitor ambient air quality. CIMIS data have been used in many research projects whose benefits go beyond the scope of this report. In addition, the secondary benefits from reductions in irrigation runoff, pesticide drift and agricultural water use have significant multiplier effects.

\section{Should CIMIS be public or private?}

Private-sector benefits would seem to justify public expenditures for CIMIS. However, the state may wish to reassess its role in managing and financing its share of the program. Alternative structures include user charges and privatization. While issues of ownership preclude charging for or privatizing the local portions of the system, the state could charge for information from its own weather stations and institute a fee for access to the statewide computer network. Alternatively, these portions of the system could be privatized.

User fees. There are a number of scenarios and potential fee structures under which CIMIS users could be charged (table 2). Problems include the need to create an accounting system to collect and handle the fees, the need to differentiate between state-owned and local sources of information, the potential for sharing information (similar to software piracy issues), and the loss of some users who will not be willing to pay a fee.

When considering these options, DWR must look at the ability of users to pay for services. More importantly, it must consider the lost private and public benefits that could result from decreased use. Charging users for CIMIS information could offset operating costs, but would slow adoption and discourage water conservation. In addition, user charges could slow the diffusion of CIMIS into nontraditional applications. Further, DWR could face equity concerns in identifying and charging for the diversity of CIMIS uses.

Privatization. On the other hand, privatization of DWR's share of CIMIS would reduce the state's costs and might make the system more flexible and responsive to users. For example, private companies could tailor the data to their client needs. The private sector already profits by refining and selling CIMIS data, sometimes in conjunction with a range of other services and technologies. If, as one consultant put it, CIMIS were run "like a business rather than a bureaucracy," it would be more responsive to customers. While we would expect an initial decrease in use if customers were charged, we might then see use increase from more aggressive marketing and responsive service packages.

However, if the CIMIS network were broken up under a privatization plan, there would be a loss in benefits currently generated by the standardized statewide system. Many growers, consulting firms, researchers and pub- lic agencies use multiple stations across many areas. For example, a statewide network is important to IPM users, who track pest emergence. If the system were not maintained as one unit, or if uniformity of data across the state and over time were compromised, these users might lose the benefits they had enjoyed under the public agency.

Diffusion of a new technology is a continuous process. Many CIMIS users take advantage of the system to cheaply learn how to manage irrigation more efficiently, which can be considered a public good. The program helps to educate growers about the value of weather information for irrigation management. Some growers (most often of highvalue or water-sensitive crops) will see enough value from such information to install and customize their own weather-and soil-monitoring systems. CIMIS provides the educational process to lead these growers on the path to precision agriculture methods. Growers of low-value and water-tolerant crops may find the value of CIMIS to be marginal and choose to discontinue its use. The majority of growers fall between these two extremes, and a statewide CIMIS program will continue to provide benefits to them.

\section{Benefits of access to CIMIS}

Our analysis of CIMIS finds that it provides significant benefits to California through both traditional and unexpected applications. Decision-makers will need to take this array of benefits into account when deciding how the system will meet the state's future needs. Large revenue benefits to farmers and urban irrigators, educational and informational benefits from research, and the many other direct and indirect benefits from CIMIS suggest that it has monetary and environmental value to California that might be reduced if users are charged. The source of the charges, whether levied by a state agency or the private sector (were CIMIS to be privatized), would not change the outcome. 
The surprising number of alternative uses for CIMIS provides an impetus for additional research on the intended and unintended benefits of this type of public program. There is also a need for additional work to provide a more inclusive analysis of users accessing data through alternative outlets (such as newspapers, radio, ATI Net, and other sources) and of the multiplier effect from information sharing.

D. Parker is Associate Professor and Extension Economist, Department of Agricultural and Resource Economics, University of Maryland, College Park, was Extension Economist, Department of Agricultural and Resource Economics, UC Berkeley, when this research was performed; D.R. Cohen-Vogel is Visiting Research Associate, Vanderbilt Institute for Public Policy Studies; D.E. Osgood is Graduate Research Associate, Department of Agricultural and Resource Economics, UC Berkeley; and D. Zilberman is Professor and member of the Giannini Foundation, Department of Agricultural and Resource Economics, UC Berkeley. This project was supported by the California Department of Water Resources, Water Gonservation Division, and the Giannini Foundation. We thank Atoosa Guity, John Muszynski, Fred Smith and Mike Troy for their assistance.

\section{References}

Cohen D, Osgood D, Parker D, Zilberman D. 1998. The California Irrigation Management Information System (CIMIS): Intended and unanticipated impacts of public investment. Choices, 3rd qtr:20-5.

Grattan SR, Bowers W, Dong A, et al. 1998. New crop coefficients estimate water use of vegetables, row crops. $\mathrm{Cal} \mathrm{Ag}$ 52:16-24

Osgood D, Cohen D, Parker D, Zilberman D. 1997. Forecasting the production benefits and incidence of a public program: An integrated survey and estimation procedure applied to study the California Irrigation Management Information System. Adv Economet 12:303-17.

Parker D, Zilberman D. 1993. Hedonic estimation of quality factors affecting the farm-retail margin. Amer J Agric Econ 7:458-66.

Parker D, Zilberman D. 1996. The use of information services: The case of CIMIS. Agribusiness 12:209-18.

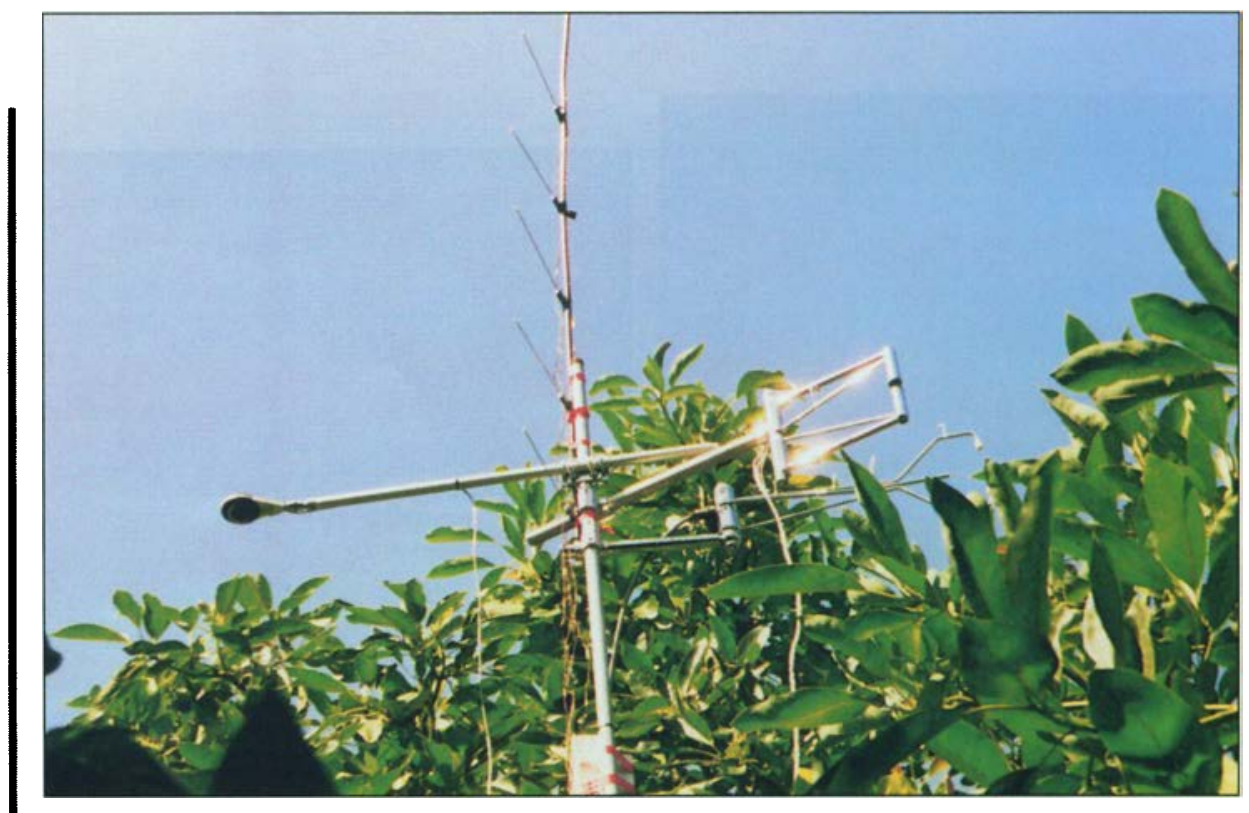

Energy balance measurements over an avocado orchard near Camarillo to estimate evapotranspiration.

\title{
Avocado and citrus orchards along the coast may use less water
}

\author{
Mark E. Grismer a Richard L. Snyder $\square$ Ben A. Faber
}

Most citrus and avocado wateruse studies have been conducted in inland orchards; however, orchards located in coastal areas are subject to cooler temperatures and foggier atmospheric conditions. To develop coastal area crop coefficients (Kc values) for irrigation management, we measured orchard consumptive water use (ETC) from two different commercial orchards located near Ventura. In addition to coastal cllmate variability, the ETc measurements were complicated by the wide variability in field soil, slope and elevation. On average, we measured Kc values of 0.46 for young lemons, 0.52 for mature lemons and 0.64 for mature avocados. These values were slightly less than those published, perhaps as a result of greater fog conditions in the orchards as compared to those occurring at the nearest reference ET stations.
Urbanization of Southern California coastal regions continues to press the remaining agricultural sector to use water more efficiently in orchard production. Orchards and other permanent crops are of particular concern because they require water year-round and cannot be economically "fallowed" during drought years, when municipal water demands may reduce agricultural water allocations. Although citrus groves once covered the southern valleys of the state, the remaining citrus and avocado groves are now largely found in the inland valleys east of Riverside, Orange and San Diego counties and along the coast from Ventura to San Luis Obispo. The growing conditions of these two areas differ because reference evapotranspiration (ETo) of the inland valleys is greater and more variable due to increased temperatures and reduced fog conditions as compared to the coastal areas.

In general, there is limited wateruse data available for citrus and avo- 